\title{
Ovarian cancer recurrence update
}

Ovarian cancer is one of the leading causes of death from gynecologic origin $(1,2)$. The diagnosis is often obtained at advanced stage disease and even if an optimal debulking is achieved almost $2 / 3$ of patients develop a recurrence (3).

The ovarian cancer recurrence often represents a treatment challenge $(4,5)$. Depending on site of recurrence, patients' clinical conditions and time of relapse, the treatment options are different both medical and surgical. The medical and technological innovations allowed new strategies with the aim to offer better options for the treatment of these patients $(6,7)$.

The present focused issue is aimed to give an overview of the last's novelties about ovarian cancer recurrence treatment. Some specific debated points and some novelties in this specific field have been addressed by experienced authors.

The issue opens with the first part dedicated to the early detection of recurrent ovarian cancer with the article by Vascone et al. entitled "Role of ultrasound in early detection of recurrent ovarian cancer: a review of the literature". The second article of the section is "Role of biomarkers for early detection of ovarian cancer recurrence" by Giampaolino et al. The second part of the issue is dedicated to surgical and medical treatment and start with the article entitled "Surgery vs. chemotherapy for ovarian cancer recurrence: what is the best treatment option?" by Capozzi et al. following the article "Secondary and tertiary ovarian cancer recurrence: what is the best management?" by Laganà et al. and the last article of this section entitled "Laparotomy vs minimally invasive surgery for ovarian cancer recurrence" by Uccella et al. The third and last part of the issue is dedicated to the novelties and innovation available for ovarian cancer recurrence treatment and start with the article entitled "Loco regional treatment for ovarian cancer recurrence" by Cianci et al. and the article entitled "Development of new medical treatment for ovarian cancer recurrence" by Vizza et al.

I would like to thank all authors for these fine and up-to-date articles.

\section{Acknowledgments}

Funding: None.

\section{Footnote}

Provenance and Peer Review: This article was commissioned by the editorial office, Gland Surgery for the series "Ovarian Cancer Recurrence". The article did not undergo external peer review.

Conflicts of Interest: The author has completed the ICMJE uniform disclosure form (available at http://dx.doi.org/10.21037/ gs-2020-ocr-08). The series "Ovarian Cancer Recurrence" was commissioned by the editorial office without any funding or sponsorship. SC serves as an unpaid editorial board member of Gland Surgery from Aug 2019 to Jul 2021 and served as the unpaid Guest Editor of the series. The author has no other conflicts of interest to declare.

Ethical Statement: The author is accountable for all aspects of the work in ensuring that questions related to the accuracy or integrity of any part of the work are appropriately investigated and resolved.

Open Access Statement: This is an Open Access article distributed in accordance with the Creative Commons AttributionNonCommercial-NoDerivs 4.0 International License (CC BY-NC-ND 4.0), which permits the non-commercial replication and distribution of the article with the strict proviso that no changes or edits are made and the original work is properly cited (including links to both the formal publication through the relevant DOI and the license). See: https://creativecommons.org/ licenses/by-nc-nd/4.0/.

\section{References}

1. Tozzi R, Giannice R, Cianci S, et al. Neo-adjuvant chemotherapy does not increase the rate of complete resection and does 
not significantly reduce the morbidity of Visceral-Peritoneal Debulking (VPD) in patients with stage IIIC-IV ovarian cancer. Gynecol Oncol 2015;138:252-8.

2. Leitao MM Jr, Chi DS. Surgical management of recurrent ovarian cancer. Semin Oncol 2009;36:106-11.

3. Fagotti A, Costantini B, Gallotta V, et al. Minimally invasive secondary cytoreduction plus HIPEC versus open surgery plus HIPEC in isolated relapse from ovarian cancer: a retrospective cohort study on perioperative outcomes. J Minim Invasive Gynecol 2015;22:428-32.

4. Lee CK, Lord S, Grunewald T, et al. Impact of secondary cytoreductive surgery on survival in patients with platinum sensitive recurrent ovarian cancer: analysis of the CALYPSO trial. Gynecol Oncol 2015;136:18-24.

5. Bristow RE, Puri I, Chi DS. Cytoreductive surgery for recurrent ovarian cancer: a meta-analysis. Gynecol Oncol 2009;112:265-74.

6. Petrillo M, De Iaco P, Cianci S, et al. Long-Term Survival for Platinum-Sensitive Recurrent Ovarian Cancer Patients Treated with Secondary Cytoreductive Surgery Plus Hyperthermic Intraperitoneal Chemotherapy (HIPEC). Ann Surg Oncol 2016;23:1660-5.

7. Ferrandina G, Legge F, Salutari V, et al. Impact of pattern of recurrence on clinical outcome of ovarian cancer patients: clinical considerations. Eur J Cancer 2006;42:2296-302.

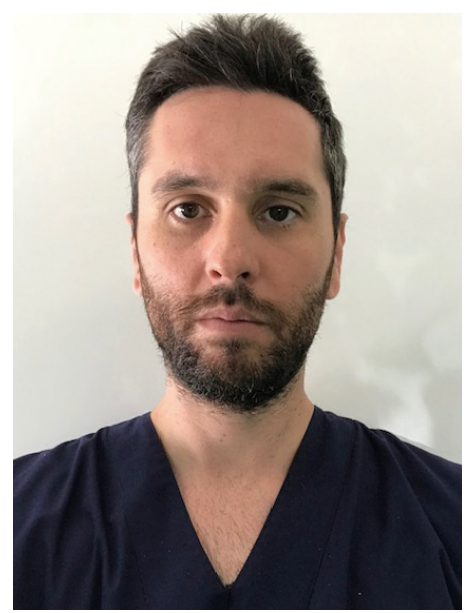

Stefano Cianci

Stefano Cianci, MD, PhD

Department of Woman, Child and General and Specialized Surgery, University of Campania

"Luigi Vanvitelli", Largo Madonna delle Grazie, Naples, Italy. (Email: stefano.cianci@unicampania.it)

Submitted Jul 06, 2020. Accepted for publication Jul 16, 2020

doi: $10.21037 / g s-2020$-ocr-08

View this article at: http://dx.doi.org/10.21037/gs-2020-ocr-08

Cite this article as: Cianci S. Ovarian cancer recurrence update. Gland Surg 2020;9(4):1090-1091. doi: 10.21037/gs-2020ocr-08 